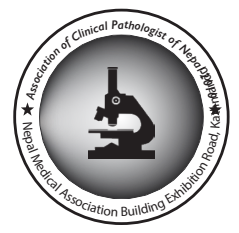

\title{
A simple and cost effective technique for construction of tissue microarrays
}

\author{
Umasankar $\mathrm{P}^{1}$, Poornima Vijayan ${ }^{1}$, Hazwa K Hamza ${ }^{1}$, Asiq Sideeque ${ }^{1}$, Anupama \\ Ponniah $^{1}$
}

${ }^{I}$ Department of Pathology, MES medical college, Perinthalmanna, Kerala, India.

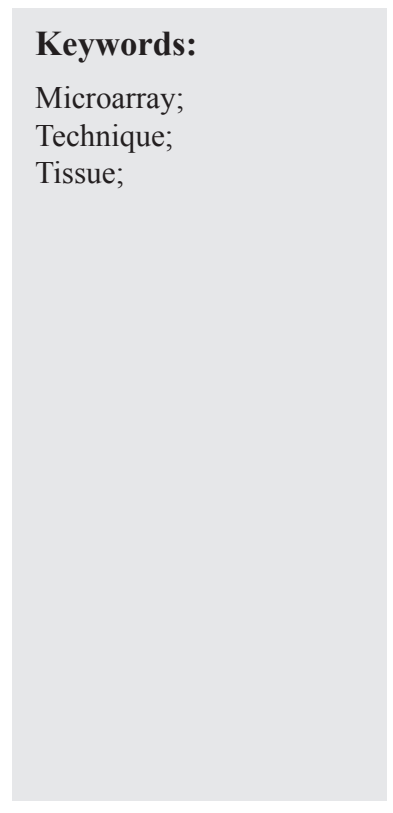

\begin{abstract}
Background: Tissue microarray is widely used in histopathology and biomedical research. Construction of tissue microarray can help institutes to considerably reduce, cost of consumables, skilled man power needed and time needed in performing high output research. However resource poor centers in developing countries have hardly any access to such techniques. The aim of this research is to develop simple, cost effective technique for making tissue microarray.
\end{abstract}

Materials and methods: Materials available in a standard pathology laboratory such as skin punch biopsy needle, bone marrow aspiration needle, trephine biopsy needle, stylet, paraffin wax, hot air oven, slide warming table, drawing pin and measuring scale were used in developing this tissue microarray. The tissue array thus developed was sectioned using a standard microtome. Immunohistochemical studies were also performed on these tissue array sections which yielded satisfactory results.

Results: This technique for construction of TMAs is simple and cost effective. When 3.5 to $3 \mathrm{~mm}$ cores were used we were able to construct arrays up to 32 cores in one block. When $1 \mathrm{~mm}$ cores were used we were able to construct arrays with 100 representative cores in one block. Morphological identification, histological typing and grading could be done in TMA sections

Conclusion: Tissue microarray is a relatively recent innovation in the field of pathology. We hope that our technique will encourage the younger researchers to take up research projects of large sample size requiring molecular studies with significantly lesser economic burden and thus leading to a significant acceleration in the transition of basic research findings into clinical applications.

\section{Correspondence:}

\section{Dr. Poornima Vijayan}

Assistant professor, Department of Pathology,

MES medical college, Perinthalmanna, Kerala, India - 679322

Email: poornima2785@gmail.com

ORCID ID: 0000-0001-8837-8718

Received : December 17 $7^{\text {th }} 2017$; Accepted : March $7^{\text {th }} 2018$; Published : $30^{\text {th }}$ March 2018

Citation: Umasankar P, Vijayan P, Hamza HK, Sideeque A, Ponniah A. A simple and cost effective technique for construction of tissue microarrays. J Pathol Nep 2018;8: 1265-70. doi: 10.3126/jpn. v8i1.19449

Copyright: This is an open-access article distributed under the terms of the Creative Commons Attribution 4.0 International License, which permits unrestricted use, distribution, and reproduction in any medium, provided the original author and source are credited.

\section{INTRODUCTION}

Tissue micro arrays are important tools for researchers in the fields of histopathology and molecular biology. TMAs can help to do research in large number of cases at same time, considerably saving resources such as skilled manpower, time required and expensive consumables such as IHC reagents. In short TMAs enable researchers to conduct their studies on large sample sizes with considerably less amounts of resources. Techniques for constructing TMA made rapid progress from Battifora's multitumor sausage to present day ultrahigh density arrays that can hold 10000 samples per block. ${ }^{1-4}$ High precision automated devices were developed. ${ }^{2,5}$ But most of these complex techniques remained beyond the reach of centers in developing 


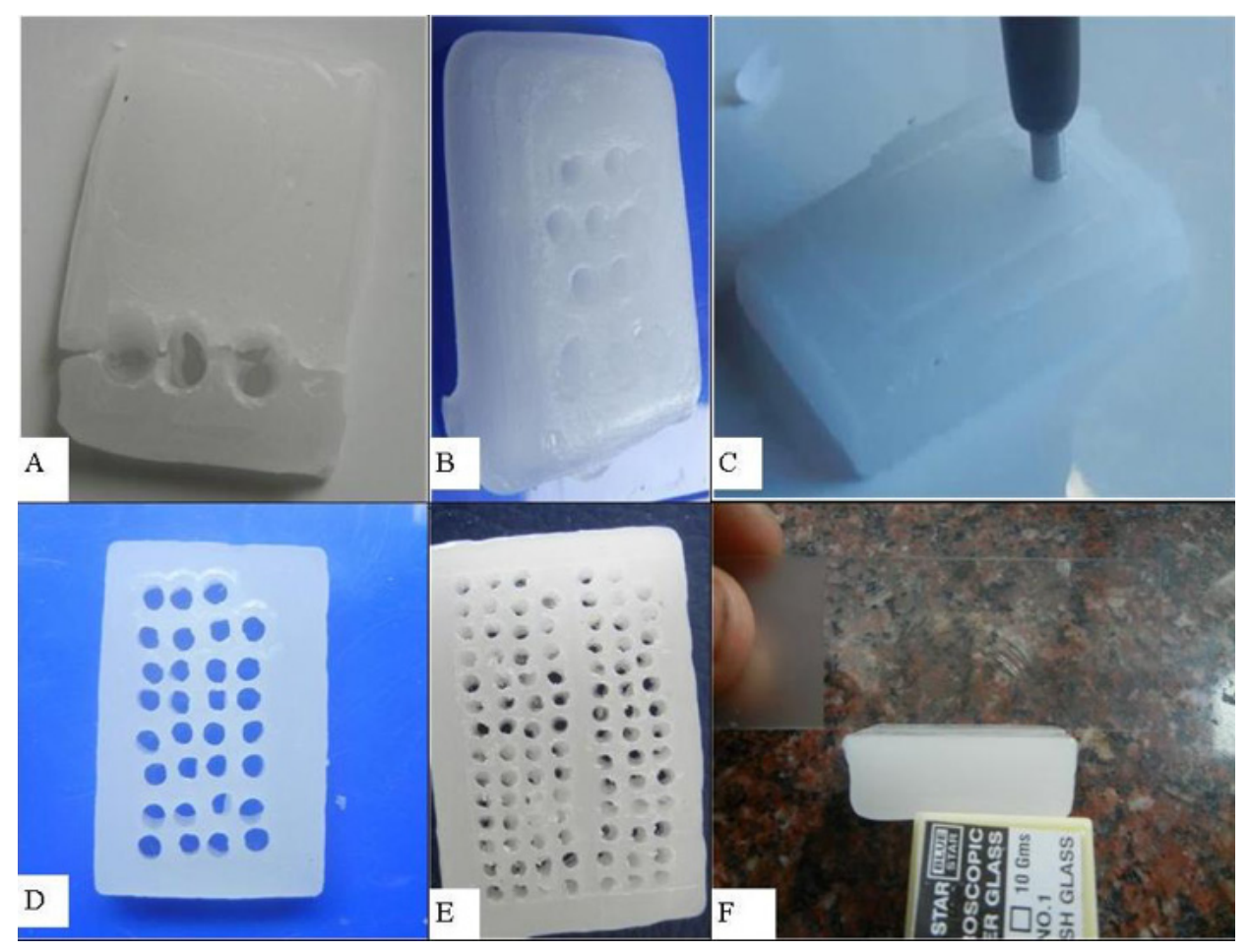

Figure 1: (A)Punching a cold wax produces cracks (B) Punching warm wax block results in depressions in the cutting surface. $(C \& D)$ Recipient blocks having $8 \times 4=32$ and $7 x 14=98$ slots (E) Making sure that anterior surface is exactly flat.

countries, mainly due to economical constrains.

Our institute is a tertiary care center located in rural area in Kerala, India. We had little access to commercial TMA kits or automated devices, since most of these devices are costly. Hence we decided to develop in-house technique for constructing TMAs using various materials readily available in the hospital so as to encourage meaningful research in the institution.

\section{MATERIALS AND METHODS}

The study was conducted in the Department of Pathology, M.E.S Medical College, Perinthalmanna, Kerala. The study was approved by the institutional ethics committee. Materials we used in the technique include skin punch biopsy needles of various bores varying from $3.5 \mathrm{~mm}$ to $1 \mathrm{~mm}$, bone marrow aspiration needle, bone marrow trephine biopsy needle, the stylets, drawing pins, metric scale, transparent plastic sheet and paraffin wax. We also utilized some basic infrastructure available in the histopathology lab such as the hot air oven, slide warming table and microtome.

Construction of a recipient paraffin block was the first step. We made paraffin blocks by pouring molten wax into ' $\mathrm{L}$ blocks' or cassettes. When blocks were set and cool, using punch biopsy needles holes of the necessary diameter were made. But much to our dismay, the technique lead to development of cracks in the recipient blocks (fig.1A).
So we modified the technique by piercing the blocks when the wax is set, but still warm. Now we were to able pierce through the wax without cracking it. But then we had another challenge. Repeated piercing in the warm wax block lead to depressions and unevenness of the cutting surface. Unevenness of the cutting surface will result in incomplete representation or absence of many tissue cores in the sections (fig. 1B). We devised two solutions. One was to pierce from posterior aspect of the blocks, resting the cutting surface on a flat plane such as glass plate or tile (fig. 1C). Other technique was to make the cutting surface of the block exactly flat using microtome, after making the holes through anterior (cutting) surface itself. Metric scale and drawing pin was used to draw coordinates on the surface so that the holes are aligned in coordinates. This made identification and numbering of the slots possible.

Next step was to identify the area of interest on a paraffin embedded tissue block. The area of interest is identified on the H\&E stained slide by the pathologist, looking through microscope. Area of interest is encircled using permanent marker pen, by looking through the light microscope (under the scanner power). A piece of transparent plastic sheet measuring $3 \times 2 \mathrm{cms}$ was placed over the $\mathrm{H} \& \mathrm{E}$ slide. An outline of the entire tissue section was made on the transparent plastic sheet, by super imposing the sheet over the slide (using a permanent marker pen, fig. 2A-C). The area of interest was also marked over the plastic sheet by encircling the area using the marker pen. The corresponding 


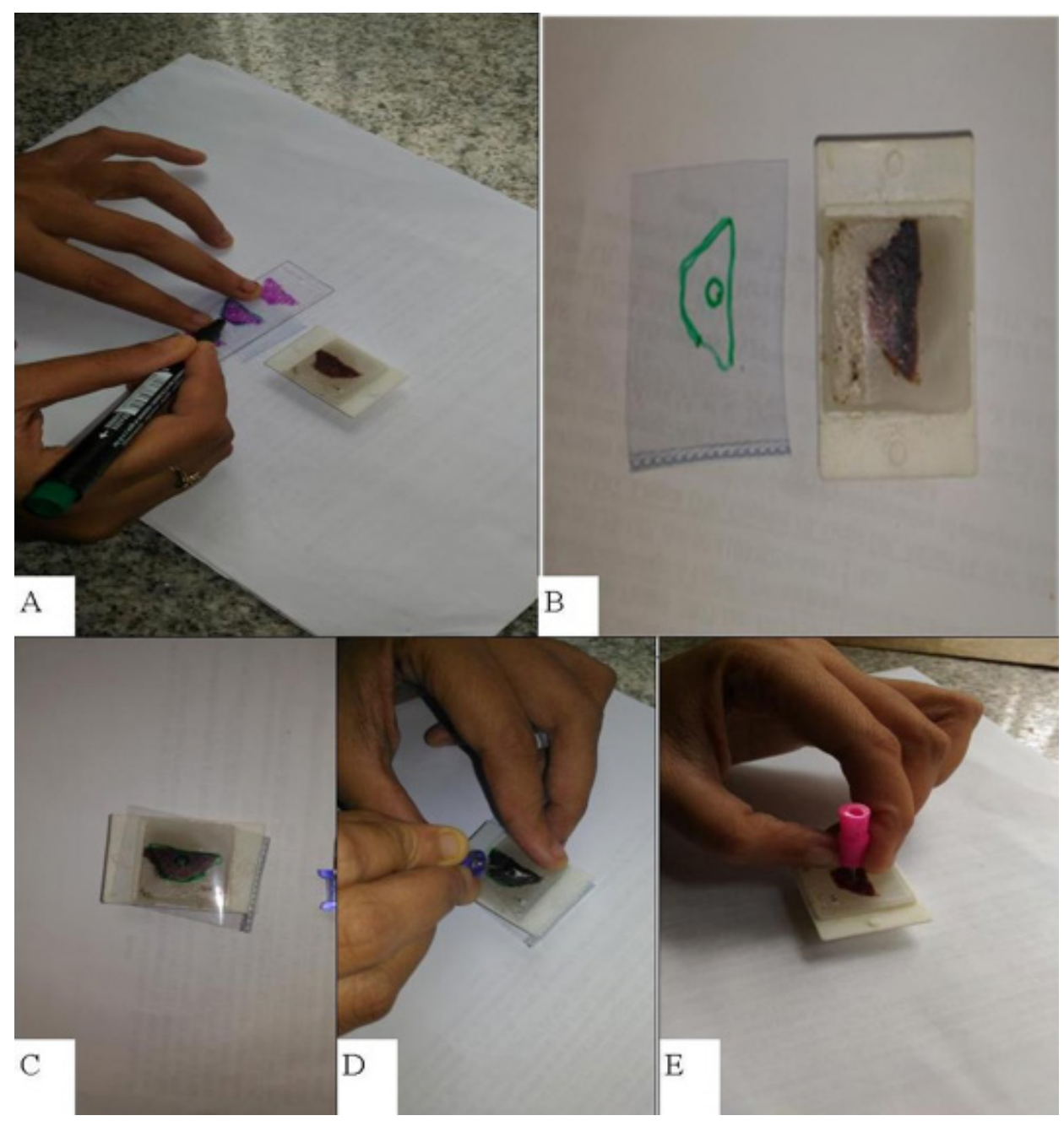

Figure 2: $(A \& B)$ Area of interest is encircled on the slide by looking under microscope. A plastic sheet is superimposed on the H\&E slide. Outline of section is drawn using a marker pen. Area of interest is also marked. (C) The plastic sheet is superimposed on the corresponding tissue embedded paraffin blocks. Outlines in the sheet and block are matched. (D) Area of interest is marked using a drawing pin. (E) Area of interest is punched out using skin punch biopsy needle.

paraffin embedded tissue block was taken. The plastic sheet with outlines of section and the area of interest was superimposed over the block. Shapes and contours of the outline on the plastic sheet were compared with that of the block and exact alignment was attempted. So we have the block and the plastic sheet with the outline marked, superimposed over the tissue. The exact area of interest was marked over the block by making marks on the block using a drawing pin, piercing through the encircled 'area of interest' marked on the superimposed plastic sheet (Fig. 2A-C). By the above detailed method we had our area of interest marked on the block.

Next step was to transfer the area of interest from 'donor block' to the 'recipient block'. Skin punch biopsy needles, trephine biopsy needle or bone marrow aspiration needle were used for the purpose. If needle had beveled tip, it was made even by using metal cutters. The area of interest was punched out, and the same was inserted into the recipient blocks, by pushing them with help of stylets (fig. 2D, E).
Insertion was done through the flat anterior (cutting) surface of the recipient block. A register was maintained to identify the position of slots and the tissue in that slot. When all the cores were inserted into the recipient block, the block was turned down, so that the anterior or cutting surface faces an exactly flat surface, such as a glass sheet or a tile (fig. 3A). Then we pushed the inserted cores through the posterior aspect so that, TMAs get aligned perfectly on a plane on the cutting surface (fig. 3A). Molten wax was poured on the posterior aspect and was smeared on the cutting surface. We attempted taking tissue sections from these blocks using microtome. But then we observed two snags 1) loss of some of the TMAs, leaving holes in the sections 2) folding of TMAs. We understood that the reason was lack of binding between the TMAs and the 'recipient' blocks. We got rid of the snags by heating the blocks with inserted arrays at $65 \mathrm{C}$ for 5-7 minutes each twice, in hot air oven. Melting and binding of paraffin in the TMA cores and recipient block was ensured by the aforementioned procedure. 


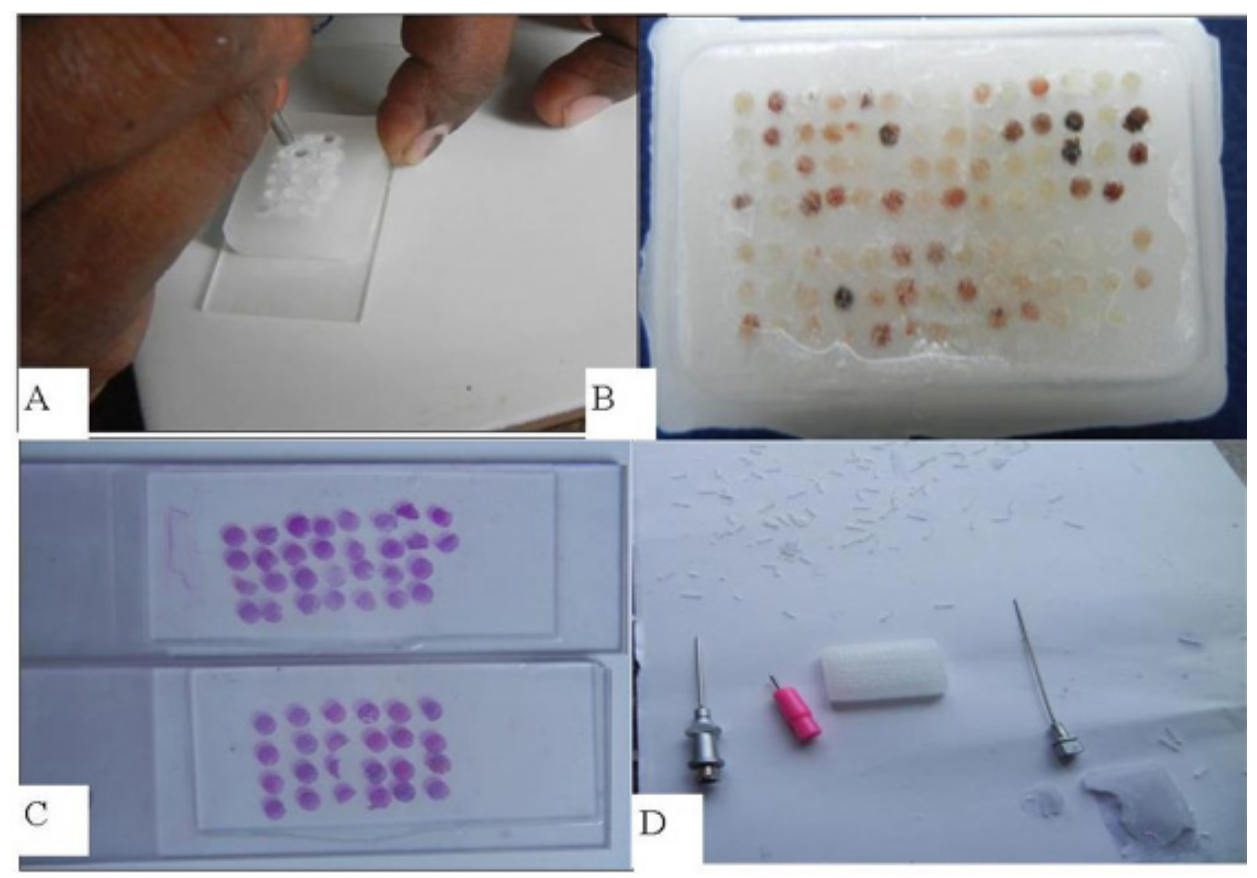

Figure 3: (A) Cores are pressed from the posterior aspect after keeping them on a flat surface, so that they get aligned on the anterior aspect. (B) TMA constructed by above mentioned procedure. (C) H\&E slide of TMA. (D) Skin punch biopsy needle and bone marrow aspiration needle.

With the above mentioned procedure we were able to get consistent good quality TMA sections. For the purpose of numbering and core identification, a few slots can be left blank. A data sheet of inserted cores depending on the positions and their histopathology lab numbers should always be maintained.

Our in-house protocol for construction of TMA consists of four main steps:

- $\quad$ Preparation of donor block

- $\quad$ Preparation of recipient block

- Transferring the tissue into recipient block

- Heating the recipient block - 'annealing'

\section{RESULTS}

Using the above mentioned method we were able to construct TMA sections. When 3.5 to $3 \mathrm{~mm}$ cores were used we were able to construct arrays up to 32 cores in one block . When $1 \mathrm{~mm}$ cores were used we were able to construct arrays with 100 representative cores in one block (fig. 3B, C). Most of the cores were retained in the sections. Thus we could successfully make TMAs using easily available materials like skin punch biopsy needle, bone marrow aspiration needle and other materials usually seen in most histopathology laboratories. Morphological identification, histological typing and grading could be done in TMA sections also (fig.4A,D). Immunohistochemical (IHC) analysis was also done in the TMA sections. Results were satisfactory (fig. 4 B,C,E,F).

\section{DISCUSSION}

Microarray is a basically technique for organizing minute amounts of biological samples on a solid support. Tissue microarrays are composite paraffin blocks constructed by extracting cylindrical tissue core biopsies from different paraffin donor blocks and re-embedding these into a single recipient (microarray) block at defined array coordinates. ${ }^{6}$

There are numerous advantages to tissue microarray over standard techniques. A standard histological section is $3-5 \mathrm{~mm}$ thick, and after primary diagnosis it can be cut 50100 times depending upon the skill of the histo-technician. Thus, each such archived paraffin block yields a material for a maximum of 100 assays. If this same block is processed for optimal microarray construction it could routinely be needle biopsied 200-300 times or more depending on the size of the tumor in the original block. Thus this technique essentially amplifies the limited tissue resource. TMAs provide scope for simultaneous analysis of a very large number of specimens. TMAs also ensure experimental uniformity, by ensuring that the entire cohort may be analyzed in one batch on a single slide. Hence, variables such as antigen retrieval, temperature, incubation times, washing procedure, and reagent concentration are standardized for the entire cohort. TMAs are amenable to a wide range of techniques including histochemistry, immunohistochemistry, in-situ hybridization techniques and even tissue micro-dissection techniques. Very small amounts of reagent and less number 


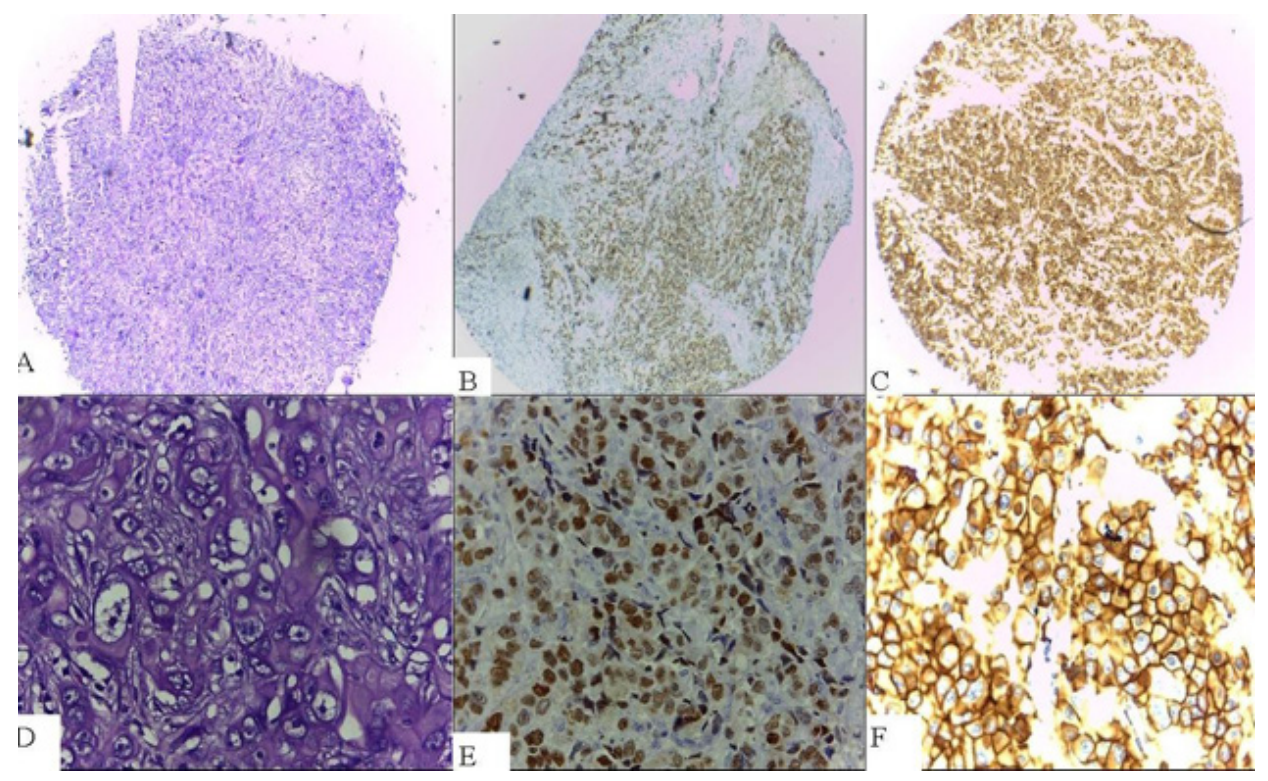

Figure 4: (A\&D) $2.5 \mathrm{~mm}$ core from carcinoma breast. Histological characteristics and grading can be done. $(B \& E)$ Progesterone Receptor IHC marker showing strong positivity in carcinoma breast $2.5 \mathrm{~mm}$ core. (C\&F) HER 2 Neu IHC marker showing 3+ positivity in carcinoma breast. (IHC stain)

of skilled laboratory personel is necessary when compared to standard techniques. Another major advantage is that the original block may be returned to the patient after retrieving few needle cores from it without destroying it. ${ }^{7}$

One of the most common arguments against tissue microarray cited is that the small cores sampled may not be representative of the whole tumor, particularly in Hodgkin lymphoma. However, many studies have showed excellent concordance between tissue microarray spots and whole sections in immunohistochemical studies of multiple tumor types. ${ }^{8}$ Parker et $\mathrm{al}^{9}$ compared the ER receptor status and found the results of microarray core for estrogen receptors (Positive/Negative) were the same as the results of the whole sections of the tumors in $96 \%$ of cases. In our institution too we conducted a pilot study on 32 cases of breast carcinoma and assessed each of their molecular subtype using our simplified tissue microarray technique. Immunohistochemical staining using ER, PR, Her2 and Ki67 were performed on TMAs and the results were concordant with those performed on whole sections.

One of the major drawbacks of tissue microarrays is its high costs which limits its use in general practice in many countries. ${ }^{10}$ Many researchers have made efforts to devise cost effective methods and have used bone marrow biopsy needle, other needles and even mechanical pencil tip needles for the same. ${ }^{11}$ Here, we too have attempted to develop a TMA technique in our institution so as to enable young researches in our institution to take up research projects involving large sample size, which they wouldn't otherwise take up due to cost factor. The technique that we have developed in our laboratory for construction of TMAs is cheap, effective, uses only infrastructure and consumables usually available in all histopathology laboratories and does not need specialized equipment. Hence this technique is suitable for use in laboratories in developing countries and resource poor centers. It can be put to good use in various research projects requiring immunohistochemistry and insitu hybridization techniques.

\section{CONCLUSION}

Tissue microarray is a relatively recent innovation in the field of pathology which is anticipated to become a widely used tool for all types of tissue-based research and has a range of potential applications in basic research, prognostic oncology and drug discovery. But, commercially available TMAs are very expensive and the beyond reach of researches, more so in developing countries like India. So, we have developed a cheap and effective technique in our laboratory for construction of TMAs using only infrastructure and consumables that are readily available in most histopathology laboratories. We hope that our technique will encourage the younger researchers to take up research projects of large sample size requiring molecular studies with significantly lesser economic burden and thus leading to a significant acceleration in the transition of basic research findings into clinical applications.

\section{ACKNOWLEDGEMENTS}

We thank Mrs Jisha, Mrs Menshi and Ms Saleena for all the help extended to aid this study.

\section{Conflict of Interest: None}




\section{REFERENCES}

1. Battifora, H.; Mehta, P. The checkerboard tissue block. An improved multitissue control block. Lab. Invest. 1990;63:722-4. Crossref

2. Vogel U. Overview on Techniques to Construct Tissue Arrays with Special Emphasis on Tissue Microarrays. Microarrays. 2014;3:1036. $\underline{\text { Crossref }}$

3. Kononen J, Bubendorf L, Kallioniemi A, et al. Tissue microarrays for high-throughput molecular profiling of tumor specimens. Nat. Med.1998;4:844-7. Crossref

4. LeBaron MJ, Crismon HR, Utama FE, et al. Ultrahigh density microarrays of solid samples. Nat. Meth. 2005;2:511-3. Crossref

5. Vogel UF; Bueltmann B. Simple, inexpensive, and precise paraffin tissue microarrays constructed with a conventional microcompound table and a drill grinder. Am J Clin Pathol 2006;126:342-8 Crossref

6. Wang H, Wang H, Zhang W, Fuller GN. Tissue microarrays: applications in neuropathology research, diagnosis, and education. Brain Pathol. 2002;12:95-107. Crossref
7. Jawhar NMT. Tissue Microarray: A rapidly evolving diagnostic and research tool. Annals of Saudi Medicine. 2009;29:123-7. doi:10.4103/0256-4947.51806 Crossref

8. Parker RL, Huntsman DG, Lesack DW, et al. Assessment of interlaboratory variation in the immunohistochemical determination of estrogen receptor status using a breast cancer tissue microarray. Am J Clin Pathol. 2002;117:723-8. Crossref

9. Shergill IS, Shergill NK, Arya M, et al. Tissue microarrays: a current medical research tool. Curr Med Res Opin 2004;20:707-12. Crossref

10. Singh A, Sau AK. Tissue Microarray: A powerful and rapidly evolving tool for high-throughput analysis of clinical specimens. IJCRI. 2010;1:1-6. Crossref

11. Shebl AM, Zalata KR, Amin MM, El-Hawary AK. An inexpensive method of small paraffin tissue microarrays using mechanical pencil tips. Diagn Pathol 2011;6:117. doi:10.1186/1746-1596-6-117. Crossref 